\title{
Multiple arterial grafting: Stay the course
}

\author{
Davis C. Drinkwater, Jr, MD
}

See related article on pages 597-606.

The use of a second arterial graft, primarily double internal thoracic artery (ITA) grafts, has been shown to be associated with improved long-term survivals, presumably as a result of their increased patency rate relative to saphenous vein grafts. These benefits have been reported in single, highvolume institution studies with a follow-up period approaching 10 years or more. ${ }^{1,2}$ In addition, substituting radial artery grafts for saphenous vein grafts may be associated with further enhanced long-term survivals in a large clinical series. ${ }^{3}$

Despite the accepted tenet that arterial grafts are a better long-term match in coronary artery bypass grafting (CABG), however, use of bilateral ITAs is limited to approximately 5\% in the United States and 12\% in Europe. ${ }^{4,5}$ There are generally acknowledged impediments to more widespread adoption, including concerns related to sternal wound healing, particularly in patients affected by diabetes or obesity, as well as the alternative generally good early and midterm results in multivessel coronary artery disease with the left ITA grafting to the left anterior descending coronary artery accompanied by saphenous vein grafts. As reflected by the low worldwide statistics, there is a selective use of a wholly or mainly arterial revascularization strategy, confined in many practices to younger patients as well as perhaps to selected "biologically youthful" older patients.

The surgical groups in the report in this issue of the Journal by Parasca and colleagues ${ }^{6}$ represent a post hoc analysis from the Synergy Between Percutaneous Coronary Intervention With TAXUS and Cardiac Surgery (SYNTAX) trial, which was an ambitious multicenter random assignment of 1800 patients with complex coronary artery disease to receive either percutaneous coronary intervention with a then-current stent device (TAXUS; Boston Scientific Corporation, Marlborough, Mass) or CABG surgery. The superiority of surgical outcomes in the management of multivessel disease has been firmly established in this trial.

From Tristar Cardiovascular Surgery, Nashville, Tenn.

Disclosures: Author has nothing to disclose with regard to commercial support.

Received for publication May 26, 2015; accepted for publication June 5, 2015; available ahead of print July 11, 2015.

Address for reprints: Davis C. Drinkwater, Jr, MD, Tristar Cardiovascular Surgery, 2400 Patterson St, Suite 307a, Nashville, TN 37203 (E-mail: davis.drinkwater@ hcahealthcare.com).

J Thorac Cardiovasc Surg 2015;150:452-3

0022-5223/\$36.00

Copyright (c) 2015 by The American Association for Thoracic Surgery

http://dx.doi.org/10.1016/j.jtcvs.2015.06.014
This current report of Parasca and colleagues $^{6}$ focuses on data extracted from the surgical arm at 5-year follow-up and uses propensity score analysis to create comparative groups, with one group receiving multiple arterial grafts versus a second with a single arterial graft, both groups with additional venous grafts as needed.

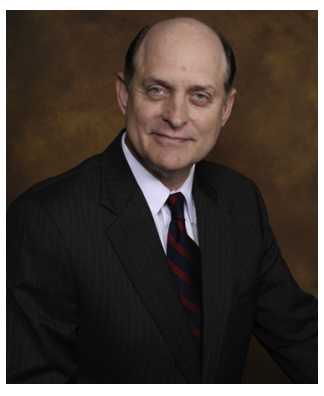
Their main finding in the matched groups, that there was no survival advantage with multiple arterial grafting at 5 years, is in keeping with most patency comparisons between arterial and venous conduits requiring between 5 and 10 years of follow-up to show a divergence. More importantly, Parasca and colleagues ${ }^{6}$ report a higher (unexpected) reintervention (mainly percutaneous coronary intervention) requirement in the multiple arterial graft group, which comprised a greater proportion of patients who both were younger and had overall lower risk scores. Cardiac catheterization and possible intervention was on an as-needed clinical basis, which may have excluded some patients with asymptomatic diabetes in either group but potentially favoring the single arterial graft group comprising older patients and those with more poorly controlled diabetes in particular. The greater reintervention rate in the multiple arterial group may also be partially explained by the perioperative data, in which it can be seen that this group of younger and healthier patients had longer cardiopulmonary bypass and aortic crossclamp times despite a greater percentage operated on with the offpump CABG technique.

This counterintuitive information underscores an inherent weakness of this multicenter trial, which is without surgical random allocation into the 2 arterial groups and included potentially varied surgical experience with nonstandardized technical and management protocols. This is in stark contrast to the previous and well-accepted reports from individual high-volume centers of the benefits of using multiple arterial bypass grafts. The technical challenges in providing the goal of complete revascularization with a mostly arterial platform and the early (up to 5 years) findings of this report may dissuade some surgical programs from more broadly offering a multiarterial CABG if they do not currently embrace it as a goal to be strived for. If not, they may be briefly comforted by the comparable outcomes with a single arterial graft complemented with saphenous vein grafts, for which the duration is too short to assess a potential divergence in graft potency. Most surgeons will likely evaluate the data and inferences in the light 
of a trial that has several significant design limitations. The lack of surgical randomization and protocols resulted in an increased use of the off-pump CABG technique in the younger multiarterial group, which raises technical questions regarding graft potency by association in patients who would also likely be acceptable candidates for cardiopulmonary bypass. Parasca and colleagues ${ }^{6}$ did not find the use of off-pump CABG to be a significant confounder, but the concern of recent reports remains. ${ }^{7}$ The lack of implementation of "optimal medical management" has been reported within both arms of the SYNTAX trial but was more significant in the CABG group from the immediate postdischarge period through the 5-year follow-up. This of course is one of the great challenges of large multicenter, international trials carried out over a lengthy period. This optimal medical management (antiplatelet drugs, statins, $\beta$ blockers, angiotensin-converting enzyme inhibitors) has been shown to lower adverse events, including mortality, and was notably absent during the 5-year follow-up, with use in approximately a third of patients undergoing CABG. ${ }^{8}$ Probably most significant are the early events, at less than 1 year, that might have been mitigated. The less optimal outcomes in the younger multiarterial grouping may be a result of some noncompliance, as well as challenges in imposing best practice principles across time zones. Specifically with regard to the radial arteries, which accounted for a lesser proportion of arterial grafts and were used in either group, there is no record of the use of pretreatment and of early vasorelaxant medications, which have clearly been shown to improve short- and long-term patency in this particular conduit.

The one concern that continues to be a source of reluctance regarding widespread adoption is for impaired sternal wound healing with bilateral ITAs, particularly in the patient with poorly controlled diabetes or obesity. ${ }^{9}$ Although the numbers at risk are relatively small, sternal infections in the patients who received bilateral ITAs may have contributed to the increased length of stay in the second arterial graft group through the presence of significant outliers. While they acknowledge a possible association, Parasca and colleagues ${ }^{6}$ cannot confirm this, because this complication was not included in the follow-up data. A recent report of bilateral ITA use in patients with obesity with a body mass index greater than $30 \mathrm{~kg} / \mathrm{m}^{2}$ has noted a trend of 3-fold increased sternal infection rate in this group. ${ }^{10}$ Unfortunately, this is an expanding demographic, and future longterm results will likely put benefits in perspective while specific ancillary sternal closure devices may be shown to provide a relative risk reduction for sternal infections and potential healing complications. Clearly in younger patients, as well as in patients with a 10-year time line, the risk and presumably greater benefits will be appropriately considered as we continue to obtain information relative to bilateral ITA use, with or without the addition of arterial grafts. The Arterial Revascularisation Trial Investigators have currently fully enrolled the first prospective randomized trial comparing single and bilateral ITA use. ${ }^{11}$ These pending results are eagerly awaited. For now, most surgeons will most likely "stay the course" on the basis of their most recent cases and influenced by previous reports of multiple arterial grafts while awaiting future, more conclusive information.

\section{References}

1. Loop FD, Lytle BW, Cosgrove DM, Stewart RW, Goormaster M, Williams GW et al. Influence of the internal-mammary-artery graft on 10-year survival and other cardiac events. N Engl J Med. 1986;314:1-6.

2. Lytle BW, Blackstone EH, Loop FD, Houghtaling PL, Arnold JH, Akhrass R, et al. Two internal thoracic arteries are better than one. J Thorac Cardiovasc Surg. 1999; 117:855-72.

3. Buxton BF, Shi WY, Tatoulis J, Fuller JA, Rosalion A, Hayward PA. Total arterial revascularization with internal thoracic and radial artery grafts in triple vessel coronary artery disease is associated with improved survival. J Thorac Cardiovasc Surg. 2014;148:1238-43; discussion 1243-4.

4. Tabata M, Grab JD, Khalpey Z, Edwards FH, O'Brien SM, Cohn LH, et al. Prevalence and variability of internal mammary artery graft use in contemporary multivessel coronary artery bypass graft surgery: analysis of the Society of Thoracic Surgeons National Cardiac Database. Circulation. 2009;210:935-40.

5. Kappetein AP, Dawkins KD, Mohr FW, Morice MC, Mack MJ, Russell ME, et al. Current percutaneous coronary intervention and coronary artery bypass grafting practices for three-vessel and left main coronary artery disease. Insights from the SYNTAX run-in phase. Eur J Cardiothorac Surg. 2006;29:486-91.

6. Parasca CA, Head SJ, Mohr FW, Mack MJ, Morice MC, Holmes DR Jr, et al. The impact of a second arterial graft on 5-year outcomes after coronary artery bypass grafting in the Synergy Between Percutaneous Coronary Intervention With TAXUS and Cardiac Surgery Trial and Registry. J Thorac Cardiovasc Surg. 2015;150:604-13.e2.

7. Takagi H, Umemoto T, All-Literature Investigation of Cardiovascular Evidence (ALICE) Group. Worse long-term survival after off-pump than on-pump coronary artery bypass grafting. J Thorac Cardiovasc Surg. 2014;148:1820-9.

8. Iqbal J, Zhang YJ, Holmes DR, Morice MC, Mack MJ, Kappetein P, et al. Optimal medical therapy improves clinical outcomes in patients undergoing revascularization with percutaneous coronary intervention or coronary artery bypass grafting: insights from the Synergy Between Percutaneous Coronary Intervention with TAXUS and Cardiac Surgery (SYNTAX) trial at the 5-year follow-up. Circulation. 2015;131:1269-77.

9. Dai C, Lu Z, Zhu H, Xue S, Lian F. Bilateral internal mammary artery grafting and risk of sternal wound infections, evidence from observational studies. Ann Thorac Surg. 2013;95:1938-45

10. Benedetto U, Montecalvo A, Kattach H, Amrani M, Raza SG, Harefield Cardiac Outcomes Research Group. Impact of the second internal thoracic artery on short- and long-term outcomes in obese patients: a propensity score matched analysis. J Thorac Cardiovasc Surg. 2015;149:841-7. e1-2.

11. Taggart DP, Altman DG, Gray AM, Lees B, Nugara F, Yu LM, et al; ART Investigators. Randomized trial to compare bilateral vs. single internal mammary coronary artery bypass grafting: 1-year results of the Arterial Revascularisation Trial (ART). Eur Heart J. 2010;31:2470-81. 